\title{
Two methods of assessing the mortality factors affecting the larvae and pupae of Cameraria ohridella in the leaves of Aesculus hippocastanum in Switzerland and Bulgaria
}

\author{
S. Girardoz ${ }^{1,2}$, R. Tomov ${ }^{3}$, R. Eschen ${ }^{1}$, D.L.J. Quicke ${ }^{2,4,5}$ \\ and M. Kenis ${ }^{1 *}$
}

${ }^{1}$ CABI Switzerland Centre, 1, rue des Grillons, 2800 Delémont, Switzerland: ${ }^{2}$ Division of Biology, Imperial College of London, Silwood Park Campus, Ascot, Berkshire, SL57PY, UK: ${ }^{3}$ Faculty of Agronomy, University of Forestry, 1756 Sofia, Bulgaria: ${ }^{4}$ Centre for Population Biology, Silwood Park Campus, Ascot, Berkshire SL5 7PY, UK: ${ }^{5}$ Department of Entomology, Natural History Museum, London SW7 5BD, UK

\begin{abstract}
The horse-chestnut leaf miner, Cameraria ohridella, is an invasive alien species defoliating horse-chestnut, a popular ornamental tree in Europe. This paper presents quantitative data on mortality factors affecting larvae and pupae of the leaf miner in Switzerland and Bulgaria, both in urban and forest environments. Two sampling methods were used and compared: a cohort method, consisting of the surveying of pre-selected mines throughout their development, and a grab sampling method, consisting of single sets of leaves collected and dissected at regular intervals. The total mortality per generation varied between 14 and $99 \%$. Mortality was caused by a variety of factors, including parasitism, host feeding, predation by birds and arthropods, plant defence reaction, leaf senescence, intraspecific competition and inter-specific competition with a fungal disease. Significant interactions were found between mortality factors and sampling methods, countries, environments and generation. No mortality factor was dominant throughout the sites, generations and methods tested. Plant defence reactions constituted the main mortality factor for the first two larval stages, whereas predation by birds and arthropods and parasitism were more important in older larvae and pupae. Mortality caused by leaf senescence was often the dominant mortality factor in the last annual generation. The cohort method detected higher mortality rates than the grab sampling method. In particular, mortality by plant defence reaction and leaf senescence were better assessed using the cohort method, which is, therefore, recommended for life table studies on leaf miners.
\end{abstract}

*Author for correspondence:

Fax: +4132421 4871

E-mail: m.kenis@cabi.org 
Keywords: Cameraria ohridella; Gracillariidae, mortality factors, parasitoids, predators, host tree resistance, leaf miners

\section{Introduction}

The horse-chestnut leafminer, Cameraria ohridella Deschka and Dimic (Lep., Gracillariidae), a moth of unknown origin, was first found in Macedonia in 1984 (Deschka \& Dimic, 1986) from where it quickly colonised the Balkans. Then, from a second focal point in Austria it spread over Central and Western Europe (Pschorn-Walcher, 1994; Gilbert et al., 2004). Since then, outbreaks have continued unabated, causing serious aesthetic damage to the European horsechestnut, Aesculus hippocastanum L., one of the favourite ornamental trees in European cities (Freise \& Heitland, 2004). Apart from aesthetic damage, it has been suggested that the pest may hamper the survival of the few remaining natural stands of horse-chestnut in the Balkans (Thalmann, 2003). A good knowledge of the main mortality factors affecting all developmental stages of $C$. ohridella is essential to develop sustainable control methods and understand the factors that allow this insect to build and maintain outbreak densities (Kenis et al., 2005). Unfortunately, mortality factors of C. ohridella are presently poorly known.

Among the mortality factors affecting the moth in Europe, parasitism has been by far the most studied (e.g. Hellrigl \& Ambrosi, 2000; Freise et al., 2002; Grabenweger, 2003; Grabenweger et al., 2005a; Girardoz et al., 2006; Volter \& Kenis, 2006). Parasitism is considered a major mortality factor in leaf miners (Hawkins et al., 1997). It was expected that, after a few years of outbreaks, native polyphagous parasitoids would adopt the host and provide at least some level of control, as often observed in invasive leaf miners (e.g. Godfray et al., 1995; Gibogini et al., 1996; Urbaneja et al., 2000). Nevertheless, although a large number of polyphagous parasitoid species have been recorded from C. ohridella, parasitism remains low in all regions and plays a minor role in the population dynamics of the moth, despite the fact that C. ohridella has been present in Europe for more than 20 years (Freise et al., 2002; Grabenweger et al., 2005a; Girardoz et al., 2007).

Apart from parasitism, there have been only a few studies that have focused on other mortality factors. Predation was investigated by Grabenweger et al. (2005b), who found that only a very limited number of arthropods prey on C. ohridella, none of them having a significant effect on population size and dynamics. Birds were also observed feeding on larvae but only 2 to $4 \%$ of the population were preyed upon. No other mortality factor has been investigated in detail, although factors such as host-feeding by parasitoids, plant defence reaction, leaf senescence before pupation and intra-specific competition may reduce the survival of leaf miner larvae in leaves.

Cameraria ohridella passes through four, occasionally five, feeding larval stages and two spinning stages before pupation in the leaves (Freise \& Heitland, 2004). There are two to four generations per year, depending on the climate, and the winter is passed as pupa in dead leaves. Life tables are an established method of studying mortality (Bellows et al., 1992), but these have rarely been used in leaf miners. A notable exception was the partial life table of Phyllonorycter crataegella (Clemens) in apple orchards by Van
Driesche \& Taub (1983) (revisited in Bellows et al. (1992) and Bellows \& Van Driesche (1999)). They used two different sampling methods to estimate parasitism, host feeding and other mortality factors affecting larval and pupal stages of $P$. crataegella, 'tagged cohorts' and 'grab samples'. The tagged cohort method consisted of the surveying of preselected mines throughout their development by regular onsite inspection. For the grab sampling method, single sets of leaves were collected and the developmental stage in the mines was determined. The effort for the cohort method probably exceeds the effort required for grab sampling, which makes the latter the most commonly used method for the assessment of mortality factors in leaf miners, including C. ohridella (e.g. Askew \& Shaw, 1979; Connor, 1991; Grabenweger, 2003; Grabenweger et al., 2005a,b; Girardoz et al., 2006). However, only if the results are equivalent can the results of the two methods be directly compared, and there is little direct evidence that this is the case.

The first main objective of the study presented here was to provide the first quantitative data on all mortality factors affecting larvae and pupae of $C$. ohridella in leaves from spring to autumn, in different environments in the Balkans and Central Europe. These data will provide the basis for full life tables, which will be presented in subsequent publications. It is hoped that they will also stimulate further studies on specific mortality factors. The second main objective was to use and compare the grab sampling and the cohort methods to provide a critical assessment of the two methods and their potential use for assessing mortality in leaf miners in different environments. In addition, these data allow us to make preliminarily comparisons of mortality factors in two different regions and in different environments. The study was carried out in Bulgaria, where horse-chestnut occurs naturally in endemic stands, and in Switzerland, where horse-chestnut is present mainly as ornamental. We expected that different mortality factors would affect their survival in Bulgaria, where C. ohridella had been found over 10 years earlier than in Switzerland. In particular, we anticipated a higher rate of natural enemies as a result of adaptation to, or recognition of $C$. ohridella as a host, which may require several years to occur (Digweed, 1998). In the two countries, studies were carried out both in urban areas and in forested areas, where mortality factors may occur at different rates.

\section{Material and methods}

Field sites

The study was carried out at six sites, two in Switzerland and four in Bulgaria. The sites were paired, each pair comprising one urban site and one in a natural environment, in or at the edge of a forest. Sites of a pair were separated by less than $40 \mathrm{~km}$ and experience rather similar climatic conditions. The first pair of sites was located in the north of Switzerland. The urban site was in the city of Basel $\left(47^{\circ} 33^{\prime} 59^{\prime \prime} \mathrm{N}, 7^{\circ} 35^{\prime} 59^{\prime \prime} \mathrm{E}\right)$ at $260 \mathrm{~m}$ a.s.l. and consisted of four mature trees in a park. Infestation was first recorded there in 2000, although C. ohridella probably arrived a few years 
earlier. The forest site was in Delémont $\left(47^{\circ} 21^{\prime} 59^{\prime \prime} \mathrm{N}\right.$, $\left.7^{\circ} 19^{\prime} 59^{\prime \prime} \mathrm{E}\right)$ at $435 \mathrm{~m}$ a.s.l. It was an alley of 54 horse-chestnut trees near a mixed forest, where the first mines of $C$. ohridella were observed in 2000. In both cases, leaf litter was left in situ over the winter. The study was carried out over two years, 2002 and 2003, at both sites. This corresponds to five generations of C. ohridella in Delémont, i.e. two in 2002 and three in 2003 and to six generations in Basel, three per year.

In Bulgaria, one pair of sites was in the city of Sofia $\left(42^{\circ} 40^{\prime} 59^{\prime \prime} \mathrm{N}, 23^{\circ} 18^{\prime} 59^{\prime \prime} \mathrm{E}\right)$, at $550 \mathrm{~m}$ a.s.l. The urban site ('Sofia park') consisted of 40 mature trees in a park and the forest site ('Sofia forest') was a stand of approximately 70 horse-chestnut trees in an urban forest composed of several broadleaf species. Infestations by $C$. ohridella were first reported in 1995 at both sites. The second pair of sites was situated in the north-east of Bulgaria. The urban site was in a park in the town of Shumen $\left(43^{\circ} 16^{\prime} 35^{\prime \prime} \mathrm{N}, 26^{\circ} 55^{\prime} 44^{\prime \prime} \mathrm{E}\right)$ at $241 \mathrm{~m}$ a.s.l. and consisted of approximately 45 trees. The forest site was located in a mixed forest of naturally growing horse-chestnuts, in between other broadleaf trees, located in the national reserve of Dervisha $\left(43^{\circ} 9^{\prime} 59^{\prime \prime} \mathrm{N}, 26^{\circ} 48^{\prime} 59^{\prime \prime} \mathrm{E}\right)$ at an average altitude of $400 \mathrm{~m}$ a.s.l. It is assumed that C. ohridella appeared there in the 1990s. At all Bulgarian sites, leaf litter was left in situ over the winter. The study took place during the years 2002 and 2003 and, at all sites, there were three generations each year.

\section{Survival of larvae in senescent leaves}

To estimate the ability of feeding and spinning larvae to complete their development and pupate in dead leaves, 750 senescent leaves were collected at the Swiss forest site from the lower branches $(<3 \mathrm{~m})$ on over 30 different trees at the end of autumn (November 7th in 2001, October 24th in 2002). In both years, 250 mines were dissected immediately, while the rest were kept under natural conditions in the field in a gauze bag. Another 250 mines were dissected 8 to 11 days later and the last 250 approximately one month after collection. At each dissection, the proportion of larvae at each developmental stage was determined by dissection, and the mortality rate was assessed for each developmental stage.

\section{Assessment of mortality factors}

Grab samples consisted of the collection of 50 to 200 leaves per site, collected every two weeks at random on the lower part of the canopy $(<3 \mathrm{~m})$ of as many trees as possible. Five hundred mines were selected at random and dissected. For each insect examined, its developmental stage was determined using the methods developed by Freise (2001), based on head capsule width and mine size. The larvae and pupae were classified as: (1) alive; (2) dead for unknown reasons (with no sign of parasitism), host feeding, predation or any other known mortality factor; (3) predated by bird (i.e. mine entirely opened); (4) predated by an arthropod (i.e. mines partly opened; predation by arthropods was considered as a whole because the openings in the mines were not always distinguishable); (5) parasitized (i.e. when a parasitoid egg or larva was found in the mine); (6) host-fed (i.e. when a larva was found desiccated and flat, with the integument attached to the upper inner surface of the mine (Askew and Shaw, 1979)); (7) dead from a plant defence reaction (i.e. with obvious signs of necrosis around a young mine); (8) dead as a result of competition with the leaf fungus, Guignardia aesculi (Peck) Stewart (Ascomycetes); (9) dead as a result of intra-specific competition at high densities; (10) dead because of the senescence of the host leaf. Based on the results of the assessment of the survival of larvae and pupae in fallen leaves, which revealed that feeding and spinning larvae could not complete their development in fallen leaves, feeding and spinning larvae found in the last grab samples collected in autumn were considered dead due to leaf senescence. Categories 2, 8 and 9 were pooled and classified as 'other' for the analysis since the difference between these three factors was not always obvious. All C. ohridella pupae, and the larvae parasitized or dead for unknown reasons, were kept singly in Petri dishes placed in a humid box at room temperature in order to rear the adult parasitoids, which were determined to species. Emerging parasitoids were sent to taxonomists for identification (see acknowledgements). Grab samples were collected on all sites over both years.

The cohort method consisted of the selection of 400 random mines, which were surveyed regularly during their development. For each generation, 400 mines containing first instar larvae were chosen on the lower branches (max. $2 \mathrm{~m}$ above ground level). Leaves with selected mines were tagged, the position of the mines on the leaf was noted and mines were checked every week to monitor larva and parasitoid development. When mines with feeding stages of the larvae stopped growing, they were brought to the laboratory and dissected. The developmental stage was noted and the mortality factor of dead or dying larvae classified as for the grab sampling method. For all but the last generation of the season, pupae were left on the trees until the adults emerged. Two-thirds of the mines from which one month after pupation no adult had emerged were brought back to the laboratory and examined. The remaining third was left on the trees to assess the mortality of summerdiapausing pupae. In the cohort method, all larvae in senescent leaves were considered dead. The cohort method was used at all three forest sites. At the Swiss forest site, the study was carried out in 2002 and 2003, while it was only carried out in 2003 at the other sites.

The percentages of larvae and pupae killed by the different mortality factors were assessed for each generation investigated using the two methods. In the cohort method, the larvae and pupae in each of the 400 mines were assigned to one of the categories listed above. The numbers were divided by four to obtain the real mortality (Bellows et al., 1992) caused by the respective factors. The exact proportion of the mortality factors was more difficult to estimate using the grab sampling method; and, therefore, a 'life table' approach was used, i.e. real mortality rates due to the investigated mortality factor were derived from apparent mortality rates calculated for each factor at each developmental stage (Bellows et al., 1992; Bellows \& Van Driesche, 1999). The following procedure was used: (i) For each fortnightly grab sample collection, the larvae of each developmental stage were assigned to a generation. This was based on the examination of the proportion of each developmental stage during the season, on data obtained from pheromone traps placed at the sites and monitoring adult emergence. Since the generations slightly overlapped, the larvae of some developmental stages could not be assigned to a particular generation. (ii) Two or three samples 


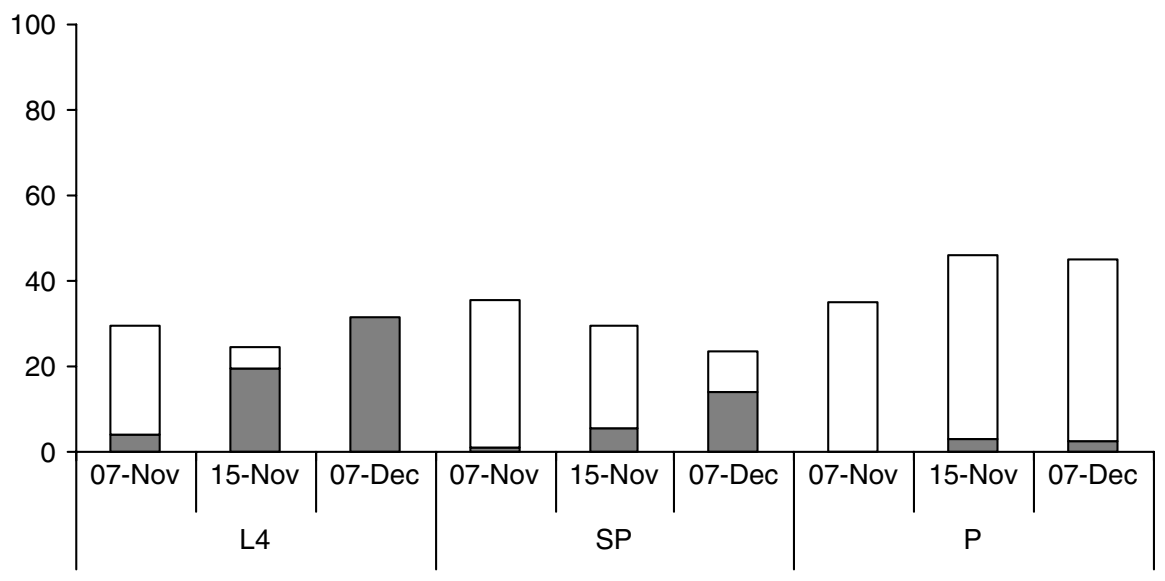

Fig. 1. Proportion and mortality rate (\%) of feeding stages (L4), spinning stages (SP) and pupae (P) of Cameraria ohridella in falling leaves in Delémont, Switzerland, collected on 7.11.2001 and examined 8 and 30 days later ( $\square$, alive; $\square$, dead).

were selected to calculate the impact of each mortality factor on each developmental stage of each generation. These were the samples where the majority of the population was at, or had just passed, the examined developmental stage, as well as one or two following samples. Sometimes only one sample was suitable for calculation at the end of the season. (iii) For mortality factor, f, acting at stage i, the apparent mortality was calculated by dividing the number of individuals who died from $\mathrm{f}$ in stage $\mathrm{i}$ by the total number of individuals in stage $i$ plus the total number of individuals of the following stages but of the same generation (stage j) (Volter \& Kenis, 2006):

$$
\mathrm{R}_{\mathrm{fi}}=\mathrm{n}_{\mathrm{fi}} /\left(\mathrm{n}_{\mathrm{i}}+\mathrm{n}_{\mathrm{j}}\right)
$$

where $R_{f i}$ is the mortality rate at stage $i$ due to factor $f, n_{f i}$ is the number of individuals of stage $i$ that died of factor $f, n_{i}$ is the total number of individuals at stage $i$, and $n_{j}$ is the total number of individuals in stage $\mathrm{j}$ (the number that survived stage i).

After the calculation of stage-specific apparent mortality rates, partial life tables were constructed. Real mortality, as defined by Bellows et al. (1992), was calculated for each stage and each factor, to allow a comparison with similar results obtained by the cohort method. The real mortality rate for a given factor was calculated as the sum of the stage-specific real mortality rates for the factor. The sum of all real mortality rates gave the total mortality of a given generation.

\section{Statistical analyses}

The effects of sampling method, generation, country, environment and mortality factor on percent mortality were analysed with a linear mixed-effects model with method, generation, country and mortality factor as fixed factors and site as random factor. Differences in mean percent larval mortality at each life stage are expressed as percent of total mortality caused by each mortality factor in each life stage and were analysed with a linear mixed-effects model with sampling method, country, year, mortality factor, life stage and environment as fixed factors and site as random factor. The effect of sampling method, country and environment on the number of parasitoid species found in each generation at each site was examined with a linear mixed effects model with method, country and environment as fixed factors and site as random factor.

Data were transformed prior to analysis in order to comply with the model assumptions where necessary. All statistical analyses were done using R 2.3.1 (R Core Development Team, 2006) using the nlme package.

\section{Results}

\section{Survival of larvae in senescent leaves}

On November 7th, 2001, the majority of leaves had already senesced. By then, C. ohridella was in its third generation but only one-third of the population had reached the pupal stage (fig. 1), and nearly all individuals were still alive. Eight days later, the majority of larvae of the last feeding stage (L4) had died, whereas most spinning stages were still alive. By the beginning of December, all L4 and most spinning stages were dead. Probably all L4 and most spinning stages had failed to reach the pupal stage in dead leaves. In 2002, at leaf senescence, C. ohridella had just completed its second generation and more than $80 \%$ of the population had already reached the pupal stage (fig. 2). As in 2001, most of the L4 and spinning stages died in the dead leaves without pupating.

\section{Mortality factors}

Total mortality of larvae and pupae was, on average, 53\% per generation. The highest mortality rate observed occurred in Switzerland, at Delémont, in the third generation of 2003 (89\% - cohorts) and in Bulgaria, in Dervisha, in the third generation of 2002 (99\% - grab samples). The lowest rates were measured in Switzerland, in Basel, in the second generation of 2002 (14\% - grab samples) and in Bulgaria, in Sofia forest, in the third generation of 2003 (23\% - cohorts).

An interacting effect of sampling method and mortality factor on mortality was found $\left(\mathrm{F}_{6,264}=6.55, P<0.001\right.$; fig. 3$)$. This is likely to be a result of more frequent detection of death due to plant defence reaction and leaf senescence with the cohort method than with the grab sampling method and more frequent detection of mortality due to parasitism with 


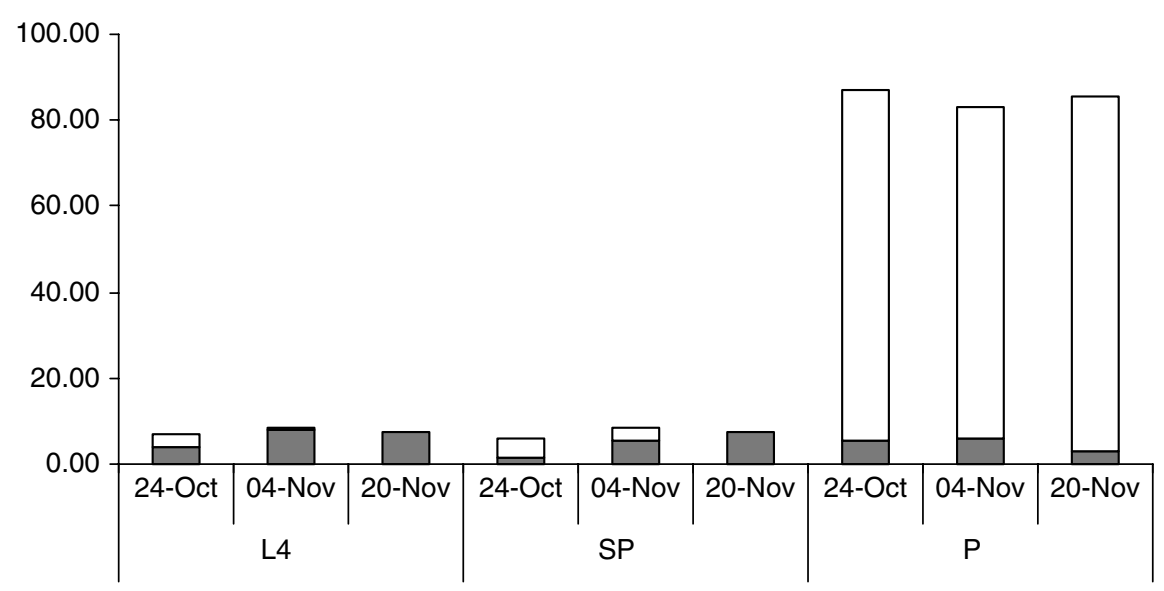

Fig. 2. Proportion and mortality rate (\%) of feeding stages (L4), spinning stages (SP) and pupae (P) of Cameraria ohridella in falling leaves in Delémont, Switzerland, collected on 24.10 .2002 and examined 11 and 27 days later ( $\square$, alive; $\square$, dead).

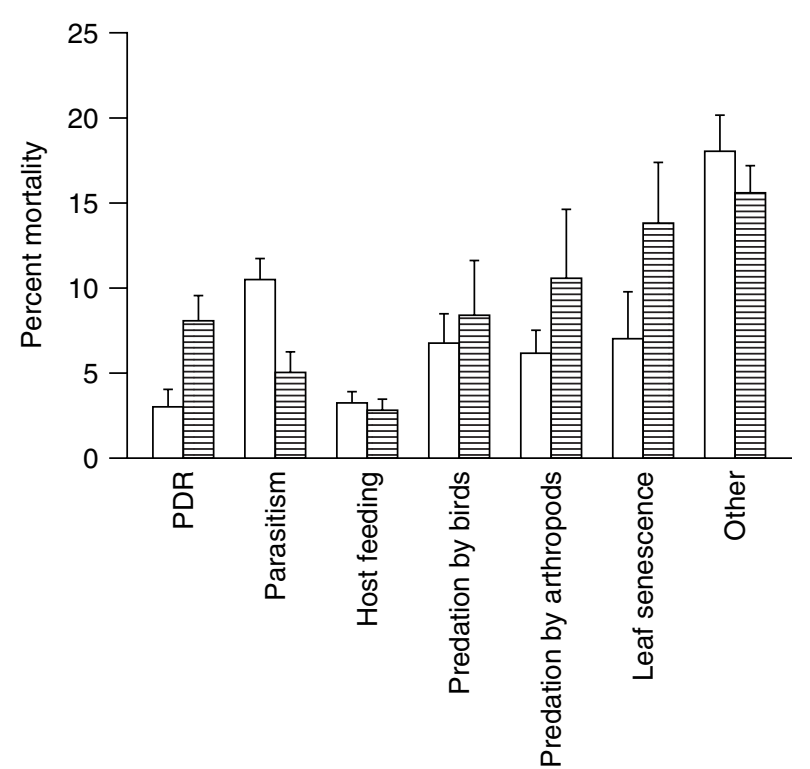

Fig. 3. Mortality rate due to the investigated factors affecting Cameraria ohridella using the grab sampling and cohort methods. PDR = plant defense reaction. Error bars indicate SE $(\square$, grab samples; 目, cohorts).

the grab sampling method than with the cohort method. Overall, mortality was detected more frequently using the cohort method than with the grab sampling method $\left(\mathrm{F}_{1,264}=17.22, P<0.001\right)$.

Mortality due to different mortality factors differed between countries (mortality factor by country interaction: $\mathrm{F}_{6,264}=17.67, P<0.001$; fig. 4). At the Swiss sites, predation by birds, leaf senescence and other factors were the most frequent cause of death of $C$. ohridella larvae; while at the Bulgarian sites, parasitism, predation by arthropods and unknown factors were the most frequently causes of death (fig. 4). Mortality due to host feeding and predation by arthropods were more frequent in Bulgaria than in

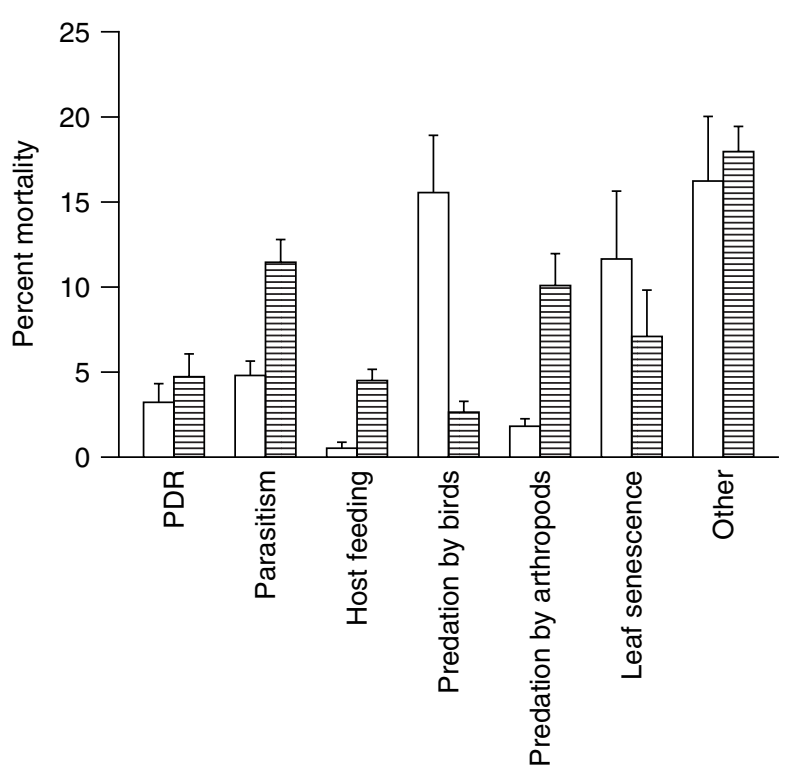

Fig. 4. Mortality rate due to the investigated factors affecting Cameraria ohridella in Bulgaria and Switzerland. PDR $=$ plant defence reaction. Error bars indicate SE. ( $\square$, Switzerland; 目, Bulgaria).

Switzerland. Mortality due to predation by birds was more frequent in Switzerland than in Bulgaria. Overall mortality did not differ significantly between the two countries $\left(\mathrm{F}_{1,2}=3.84, P>0.185\right)$.

A significant interaction between environment and mortality factor was found $\left(\mathrm{F}_{6,264}=3.79, P<0.005\right.$; fig. 5). This was likely to be the result of a higher proportion of mortality due to plant defence reaction in forest environments than in urban environments and a higher proportion of mortality due to predation by arthropods in the urban environment than in the forest environment. Overall mortality of $C$. ohridella did not differ between urban and forest environments $\left(\mathrm{F}_{1,2}=0.250, P=0.667\right)$. 


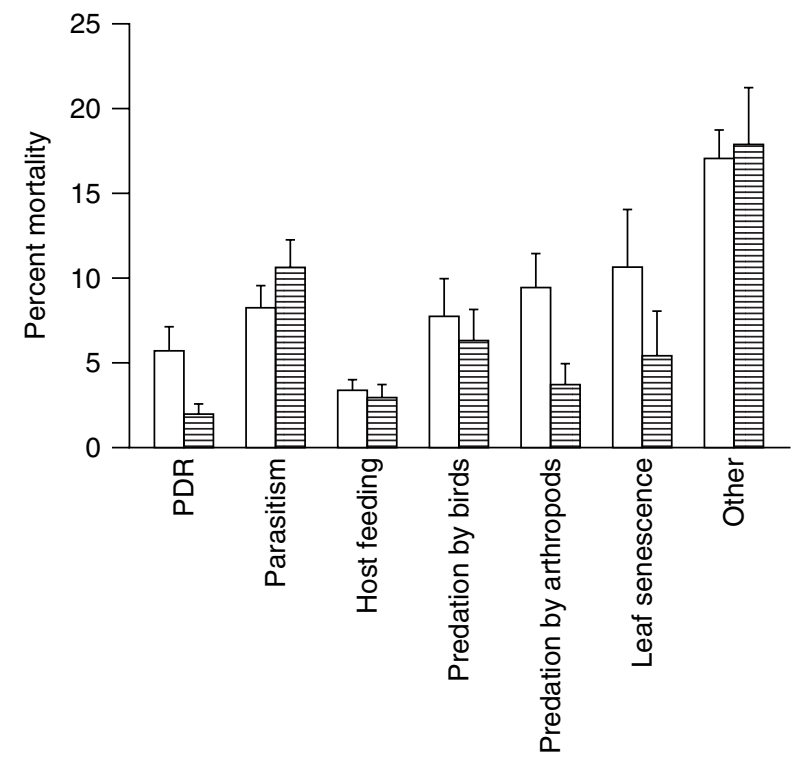

Fig. 5. Mortality rate due to the investigated factors affecting Cameraria ohridella in the urban and forest environment. PDR $=$ plant defense reaction. Error bars indicate SE $(\square$, forest sites; 目, urban sites).

The frequency of mortality as a result of different factors varied among generations (mortality factor by generation interaction: $F_{12,264}=9.62, P<0.001$; fig. 6). This interaction appears to be the result of higher mortality due to leaf senescence in the last generation than in the first or middle generation.

A significant interacting effect between sampling method and mortality factor on the percent of total mortality of larvae of different instars was found $\left(\mathrm{F}_{6,1728}=7.30, P<0.001\right.$; fig. 7). In the cohort, death of larvae of the first two developmental stages (L1 and L2) was most often due to plant defence reaction. Mortality of the developmental stages L3 and L4 was mostly attributed to predation by arthropods, and mortality of larvae at the spinning stage and pupae was most due to predation by birds. The proportion of mortality due to parasitism increased with larval development, from 5\% in L2 to $30 \%$ at the pupal stage. The results of the grab sampling method resemble those of the cohort method, but the proportion of other/unknown mortality factors was higher than with the cohort method and was the most frequent mortality category from larval developmental stage, L1, to the spinning stage. Parasitism was more frequently determined as the death factor in the case of spinning larvae and pupae than in the cohorts, while almost all other mortality factors were less frequently determined.

\section{Parasitoid species}

The parasitoid species richness per site and generation was significantly higher with the grab sampling method than with the cohort method $\left(\mathrm{F}_{1,39}=314.81, P=0.035\right.$; means $=3.57 \pm 0.29$ and $2.27 \pm 0.43$, respectively). No differences in the number of parasitoid species per site and generation were found between the two countries $\left(\mathrm{F}_{1,3}=7.11, P=0.076\right)$ and the two environments $\left(\mathrm{F}_{1,3}=0.23, P=0.663\right)$.

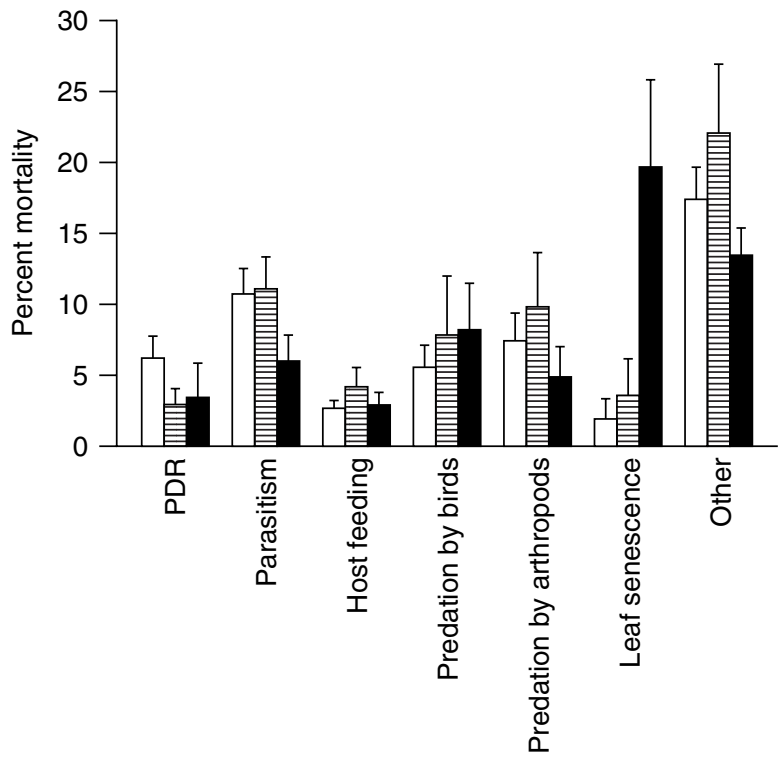

Fig. 6. Mortality rate due to the investigated factors affecting the three generations of Cameraria ohridella. PDR = plant defense reaction. Error bars indicate SE ( $\square$, first generation; 目, middle generation; $\mathbf{\square}$, last generation).

The 15 parasitoid species reared from leaves from all sites are detailed in table 1 . The major species in Switzerland were the ectoparasitoids, Minotetrastichus frontalis (Nees) and Pnigalio agraules (Walker). Both species were found mainly on the last feeding and the spinning stages. At all Bulgarian sites, the main parasitoid was the pupal endoparasitoid, Pediobius saulius (Walker).

\section{Discussion}

Mortality factors

The parasitoid complexes and parasitism rates observed during this study are very similar to those observed in previous investigations in Central Europe and the Balkans (e.g. Freise et al., 2002; Grabenweger et al., 2005a; Girardoz et al., 2006; Volter \& Kenis, 2006). Parasitism rates and host feeding rates were higher in Bulgaria than in Switzerland. Freise et al. (2002) and Grabenweger et al. (2005a) also observed higher parasitism rates in the Balkans compared to Central Europe, mainly due to the higher abundance of the pupal parasitoid, Pediobius saulius. Parasitism was not influenced by either the type of environment or the generation, which confirms previous observations by Girardoz et al. (2006).

Predation by arthropods was higher in the Balkans than in Switzerland and in forest sites than in urban sites. The higher predation rate in the forest environment could be the consequence of the surrounding vegetation, which provides a more suitable habitat for the predatory arthropods than the green parks in the cities, where our urban sites were situated. Predation by birds was higher in Switzerland (mean 16\%) than in Bulgaria (3\%) and also much higher than that observed by Grabenweger et al. (2005b), who found rates of only $2 \%$ in Austria. This may be the result of the particularly high avian predation at the Swiss forest site, where up to $41 \%$ mortality could be attributed to birds, 
Grab sample

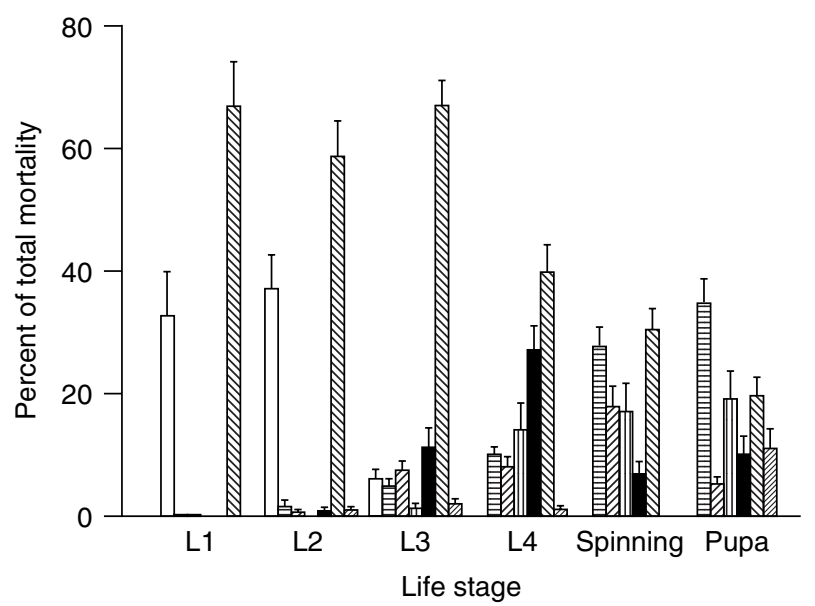

Cohort

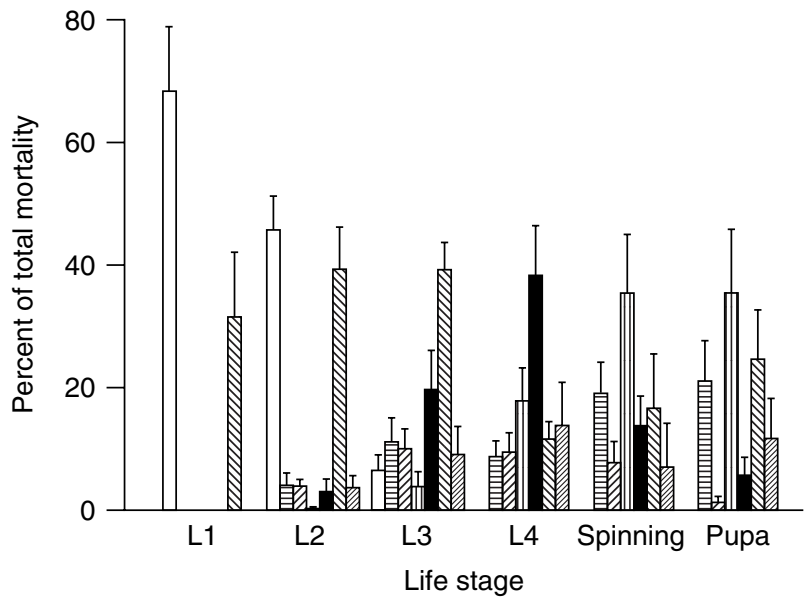

Fig. 7. Mean percentage of total mortality within each life stage caused by the investigated mortality factors. Left figure shows results of grab samples method, and right figure shows effect of the cohort method. Error bars indicate SE ( $\square$, PDR; 目, parasitism; $\square$, host feeding; 四, predation by birds; $\mathbf{\square}$, predation by arthropods; $\mathbb{N}$, other; $\mathbb{Z}$, leaf senescence).

Table 1. Parasitoid species reared from Cameraria ohridella in Switzerland and Bulgaria in the years 2002 and 2003 , using the grabsampling (g.s.) and cohort (coh.) methods

\begin{tabular}{|c|c|c|c|c|c|c|c|c|c|}
\hline & \multicolumn{6}{|c|}{ Forest sites } & \multicolumn{3}{|c|}{ Urban sites } \\
\hline & \multicolumn{2}{|c|}{ Delémont $\mathrm{CH}$} & \multicolumn{2}{|c|}{ Dervisha BG } & \multicolumn{2}{|c|}{ Sofia forest BG } & \multirow{2}{*}{$\frac{\text { Basel CH }}{\text { g.s. }}$} & \multirow{2}{*}{$\frac{\text { Shumen BG }}{\text { g.s. }}$} & \multirow{2}{*}{$\frac{\text { Sofia Park BG }}{\text { g.s. }}$} \\
\hline & g.s. & coh. & g.s. & coh. & g.s. & coh. & & & \\
\hline $\begin{array}{l}\text { Eulophidae: Eulophinae } \\
\text { Pnigalio agraules (Walker) } \\
\text { Pnigalio soemius (Walker) } \\
\text { Pnigalio pectinicornis (L.) } \\
\text { Sympiesis sericeicornis (Nees) } \\
\text { Cirrospilus viticola (Rondani) } \\
\text { Cirrospilus talitzkii (Bouček) } \\
\text { Elachertus inunctus Nees }\end{array}$ & * & * & $\begin{array}{l}* \\
* \\
*\end{array}$ & * & * & & * & * & * \\
\hline $\begin{array}{l}\text { Eulophidae: Entedoninae } \\
\text { Closterocerus trifasciatus (Westwood) } \\
\text { Neochrysocharis chlorogaster (Erdös) } \\
\text { Chrysocharis nephereus (Walker) } \\
\text { Chrysocharis pentheus (Walker) } \\
\text { Pediobius saulius (Walker) }\end{array}$ & * & $\begin{array}{l}* \\
*\end{array}$ & $\begin{array}{l}* \\
* \\
* \\
*\end{array}$ & * & $\begin{array}{l}* \\
* \\
* \\
* \\
*\end{array}$ & * & $\begin{array}{l}* \\
*\end{array}$ & $\begin{array}{l}* \\
* \\
*\end{array}$ & * \\
\hline $\begin{array}{l}\text { Pteromalidae: Pteromalinae } \\
\text { Pteromalus semotus (Walker) }\end{array}$ & & & & & * & & & & \\
\hline $\begin{array}{l}\text { Ichneumonoidea } \\
\text { Braconidae: Hexothecinae } \\
\text { Colastes braconius (Haliday) }\end{array}$ & & & * & & * & & * & & \\
\hline
\end{tabular}

mainly tits (Parus major L. and Parus caeruleus L) in some generations. It is possible that the conditions at this site are particularly favourable to birds, and it remains to be seen whether bird predation is equally high at other forest sites in Switzerland.

The higher parasitism and predation by arthropods in Bulgaria suggest that some natural enemies may have started to adapt to the alien moth in the Balkans, as compared to Switzerland where the moth arrived more recently. However, mortality rates are still far from sufficient to keep host/prey populations under control and all investigated sites suffer from unabated outbreaks. Compared to endemic leaf miners, mean parasitism rates of $13 \%$, mean predation rates of $7 \%$ and mean host feeding 
rates of $5 \%$, as observed in this study, remain very low. Askew \& Shaw (1979) report combined rates of parasitism and host feeding of $80 \%$ on an endemic Phyllonorycter sp. on oak and birch, while Faeth \& Simberloff (1981) found that more than $40 \%$ of the population of Cameraria sp. nov. died of parasitism and host feeding. Predation rates on this Cameraria sp. ranged from 10 to $30 \%$, while Urbaneja et al. (2000) mentioned a case where predation on another invasive leaf miner, Phyllocnistis citrella Stainton, reached $70 \%$.

Plant defence reaction was the main mortality factor in the first two larval instars, in both countries. Although it was apparently higher at forest sites than at urban sites, variations were often more important between neighbouring trees than between sites (S. Girardoz and R. Tomov, unpublished observations). This suggests that plan defence mechanisms in Aesculus hippocastanum are genetically based, which opens perspectives for the development of resistant cultivars. Mortality due to leaf senescence was, as expected, much more important in the last generation but was also very variable from year to year. It was negligible when the pupation period of the last generation of the moth coincided with the beginning of leaf senescence but reached up to $43 \%$ mortality when the majority of the third generation was in the larval stage when leaves died. These large variations in the mortality of larvae in the last generation may partly explain the significant changes in population densities generally observed from year to year in Europe (Girardoz et al., 2007). 'Other' mortality, which comprises unknown mortality, mortality through competition with the leaf fungus $G$. aesculi and intra-specific competition, was much higher in Bulgaria (mean 16\%) than in Switzerland (mean $8 \%$ ). These factors can easily be confused, as nothing distinguishes a larva killed by starvation from intra-specific competition or competition with the fungus. Furthermore, mortality by leaf senescence and intra-specific competition may also be confused because total defoliation, which is the result of overcrowding and, thus, intra-specific competition, results in early leaf drop. Intra-specific competition undoubtedly played a role in some years, usually in the last generation, e.g. in Bulgaria at all sites in 2002, in Basel in 2002 and Delémont in 2003.

The results of the present study provide the first quantitative assessment of mortality factors occurring simultaneously on larvae and pupae of the horse-chestnut leaf miner, C. ohridella. Although the low number of sites investigated does not allow firm conclusions regarding variations in mortality factors between countries and environments, these data should stimulate further studies on specific mortality factors that may lead to the development of new management strategies.

\section{Sampling methods}

The current study shows that the results of life table studies of leaf miners may depend on the method used to assess mortality of the larvae (Van Driesche \& Taub, 1983). Mortality as a result of plant defence reaction was more frequently detected with the cohort method than with grab sampling method. The necrosis around the mine is not immediately visible (S. Girardoz, personal observation) and is more likely to be detected using the cohort method in which the mines are surveyed over a period of time. Also, in the grab sampling method, small mines in which the larva died from plant defence reaction in the preceding weeks may have become undetectable because, in the meantime, they have been merged into a large mine. The monitoring of cohorts also measured higher rates of mortality due to leaf senescence. In particular, this method showed that leaves also drop in spring and summer, causing a mortality that was not detectable by grab sampling. Because grab sampling underestimates host plant resistance and leaf senescence, we believe that the cohort method provides a better estimation of mortality rates than does grab sampling.

However, the grab sampling method has some advantages over the cohort methods that should not be neglected. Firstly, collections of grab samples can be made at longer intervals than the monitoring of cohorts, which is a clear advantage if the field sites are far from the laboratory and resources are limited. Secondly, grab samples can be examined in the laboratory under a microscope, whereas cohorts have to be monitored in the field. Thirdly, in our experiments, cohorts were selected only once per generation, whereas in the grab sampling method, calculations were usually based on at least two, and often three, collections made at two week intervals, which probably represents a better sample of the generation investigated. In the cohort method, mines could be selected at different times to better match the period of occurrence of the target generation, but this would complicate the methodology because more field work would be required. Furthermore, the sample size can be much higher in the grab sampling method, in which different mines are examined at each sampling date, than in the cohort method, in which the same mines are followed during their development. As a result, rare mortality factors, such as uncommon parasitoid species, are more likely to be detected using the grab sampling method. Finally, it must be noted that both methods are difficult to implement when population densities are high and the leaves are virtually totally occupied by mines. However, in this situation, the cohort method is practically impossible to apply whereas, in the grab sampling method, the problem can be partly overcome by selecting the least attacked leaves, with the danger that factors such as intra-specific competition and leaf senescence will be underestimated. Thus, although the cohort method probably provides a better estimate of the mortality factors affecting the moth's larvae and pupae in leaves, especially when generations are overlapping, grab samples offer a satisfactory alternative when resources are limited, when the sites and leaves are not easily accessible or when the density of leaf miners is very high.

\section{Acknowledgements}

We thank Giselher Grabenweger (Universität für Bodenkultur, Vienna) and Hannes Bauer (Natural History Museum, Bern) for their help in the identification of parasitoids, as well as Boyan Hristov, Natalia Guazzone, Sébastien Marcombe, Ghislaine Cortat and Audrey Favereau for their help in field and laboratory work. We also thank Hefin Jones, Jon Knight, Thomas Spiegelberger, Ed Godolphin and two anonymous reviewers for fruitful discussions and comments on the manuscript, and Werner Heitland for his support during the study. The project was funded by the Swiss Federal Office for Education and Science as part of the European Union FWP5 project CONTROCAM, (QLK5-CT2000-01684) and by the EU FWP6 project ALARM (GOCECT-2003-506675). 


\section{References}

Askew, R.R. \& Shaw, M.R. (1979) Mortality factors affecting the leaf-mining stages of Phyllonorycter (Lepidoptera: Gracillariidae) on oak and birch. 1. Analysis of the mortality factors. Zoological Journal of the Linnean Society 67, 31-49.

Bellows, T.S., Jr. \& Van Driesche, R.G. (1999) Life table construction and analysis for evaluating biological control agents. pp. 199-223 in Bellows, T.S. \& Fisher, T.W. (Eds) Handbook of Biological Control. New York, Academic Press.

Bellows, T.S. Jr., Van Driesche, R.G. \& Elkinton, J.S. (1992) Life-table construction and analysis in the evaluation of natural enemies. Annual Review of Entomology 37, 587-614.

Connor, E.F. (1991) Colonization, survival, and causes of mortality of Cameraria hamadryadella (Lepidoptera: Gracillariidae) on four species of host plants. Ecological Entomology 16, 315-322.

Deschka, G. \& Dimic, N. (1986) Cameraria ohridella sp. n. (Lep., Lithocolletidae) aus Mazedonien, Jugoslawien. Acta Entomologica Jugoslavica 22, 11-23.

Digweed, S.C. (1998) Mortality of birch leafmining sawflies (Hymenoptera: Tenthredinidae): Impacts of natural enemies on introduced pests. Environmental Entomology 27, 1357-1367.

Faeth, S.H. \& Simberloff, D. (1981) Population regulation of a leaf-mining insect, Cameraria sp. Nov. at increased field densities. Ecology 62, 620-624.

Freise, J.F. (2001) Untersuchungen zur Biologie und Ökologie der Roßkastanien-Miniermotte (Cameraria ohridella DESCH. \& DIM. 1986) (Lepidoptera: Gracillariidae). PhD. Thesis, Fakultät des Wissenschaftszentrum Weihenstephan für Ernährung, Landnutzung und Umwelt. Munich, Germany, Technische Universität München.

Freise, J.F. \& Heitland, W. (2004) Bionomics of the horsechestnut leaf miner Cameraria ohridella Deschka \& Dimic 1986, a pest on Aesculus hippocastanum in Europe (Insecta: Lepidoptera: Gracillariidae). Senckenbergiana Biologica 84, $1-20$.

Freise, J.F., Heitland, W. \& Toshevski, I. (2002) Parasitism of the horse-chestnut leaf miner, Cameraria ohridella, Deschka and Dimic (Lep., Gracillariidae), in Serbia and Macedonia. Anzeiger für Schädlingskunde 75, 152-157.

Gibogini, B., Alma, A. \& Arzone, A. (1996) Bio-ethological researches on the Hymenoptera of the biocenosis of Phyllonorycter robiniellus (Clemens) (Lepidoptera: Gracillariidae). Bolletino di Zoologia agraria e di Bachicoltura 28, 13-22.

Gilbert, M., Grégoire, J.-C., Freise, J.F. \& Heitland, W. (2004) Long-distance dispersal and human population density allow the prediction of invasive patterns in the horse chestnut leafminer Cameraria ohridella. Journal of Animal Ecology 73, 459-468.

Girardoz, S., Kenis, M. \& Quicke, D.L.J. (2006) Recruitment of native parasitoids by an exotic leaf miner, Cameraria ohridella: host-parasitoid synchronisation and influence of the environment. Agricultural and Forest Entomology 8, $48-56$.

Girardoz, S., Quicke, D.L.J. \& Kenis, M. (2007) Factors favouring the development and maintenance of outbreaks in an invasive leaf miner Cameraria ohridella (Lepidoptera:
Gracillariidae): a life table study. Agricultural and Forest Entomology. In press.

Godfray, H.C.J., Agassiz, D.L.J., Nash, D.R. \& Lawton, J.H. (1995) The recruitment of parasitoid species to two invading herbivores. Journal of Animal Ecology 64, 393-402.

Grabenweger, G. (2003) Parasitism of different larval stages of Cameraria ohridella. Biocontrol 48, 671-684.

Grabenweger, G., Avtzis, N., Girardoz, S., Hrasovec, B., Tomov, R. \& Kenis, M. (2005a) Parasitism of Cameraria ohridella (Lepidoptera, Gracillariidae) in natural and artificial horse-chestnut stands in the Balkans. Agricultural and Forest Entomology 7, 291-296.

Grabenweger, G., Kehrli, P., Schlick-Steiner, B., Steiner, F., Stolz, M. \& Bacher, S. (2005b) Predator complex of the horse chestnut leafminer Cameraria ohridella: identification and impact assessment. Journal of Applied Entomology 129, 353-362.

Hawkins, B.A., Cornell, H.V. \& Hochberg, M.E. (1997) Predators, parasitoids, and pathogens as mortality agents in phytophagous insect populations. Ecology 78, 2145-2152.

Hellrigl, K. \& Ambrosi, P. (2000) Die Verbreitung der Rosskastanien-Miniermotte Cameraria ohridella Desch. \& Dimic (Lepid., Gracillariidae) in der Region SüdtirolTrentino. Anzeiger für Schädlingskunde 73, 25.

Kenis, M., Tomov, R., Svatos, A., Schlienslog, P., LopezVaamonde, C., Heitland, W., Grabenweger, G., Girardoz, S., Freise, J. \& Avtzis, N. (2005) The horse-chestnut leaf miner in Europe - prospects and constraints for biological control. pp. 77-90 in Hoddle, M. (Ed.). Proceedings of the Second International Symposium on Biological Control of Arthropods, Davos, Switzerland, 12-16 September 2005. Morgantown, WV, USA, Forest Health Technology Enterprise Team.

Pschorn-Walcher, H. (1994) Freiland-Biologie des eingeschleppten Rosskastanien-Miniermotte Cameraria ohridella DESCHKA et DIMIC (Lep., Gracillariidae) im Wienerwald. LinzerBiologische Beiträge 26, 633-642.

R Core Development Team (2006) R: A language and environment for statistical computing. Vienna, Austria, R Foundation for Statistical Computing. http://www.R-procect.org.

Thalmann, C. (2003) Effects of defoliation by horse chestnut leafminer (Cameraria ohridella) on its host Aesculus hippocastanum. PhD thesis from the Univerity of Bern, Switzerland.

Urbaneja, A., Llácer, E., Tomás, O., Garrido, A. \& Jacas, J.-A. (2000) Indigenous natural enemies associated with Phyllocnistis citrella (Lepidoptera: Gracillariidae) in eastern Spain. Biological Control 18, 199-207.

Van Driesche, R.G. \& Taub, G. (1983) Impact of parasitoids on Phyllonorycter leafminers infesting apple in Massachusetts, USA. Protection Ecology 5, 303-317.

Volter, L. \& Kenis, M. (2006) Parasitoid complex and parasitism rates of the horse chestnut leafminer, Cameraria ohridella (Lepidoptera: Gracillariidae) in the Czech Republic, Slovakia and Slovenia. European Journal of Entomology 103, $367-370$.

(Accepted 3 January 2007)

(C) 2007 Cambridge University Press 